\title{
Evolution of the postoperative sagittal spinal profile in early-onset scoliosis: is there a difference between rib-based and spine-based growth-friendly instrumentation?
}

\author{
*Zhonghui Chen, MD, Song Li, MD, Yong Qiu, MD, Zezhang Zhu, MD, Xi Chen, MD, Liang Xu, MD, \\ and Xu Sun, MD
}

Spine Surgery, Drum Tower Hospital, Nanjing University Medical School, Nanjing, Jiangsu Province, People’s Republic of China

OBJECTIVE Although the vertical expandable prosthetic titanium rib (VEPTR) and growing rod instrumentation (GRI) encourage spinal growth via regular lengthening, they can create different results because of their different fixation patterns and mechanisms in correcting scoliosis. Previous studies have focused comparisons on coronal plane deformity with minimal attention to the sagittal profile. In this retrospective study, the authors aimed to compare the evolution of the sagittal spinal profile in early-onset scoliosis (EOS) treated with VEPTR versus GRI.

METHODS The data for 11 patients with VEPTR and 22 with GRI were reviewed. All patients had more than 2 years' follow-up with more than 2 lengthening procedures. Radiographic measurements were performed before and after the index surgery and at the latest follow-up. The complications in both groups were recorded.

RESULTS Patients in both groups had similar diagnoses, age at the index surgery, and number of lengthening procedures. The changes in the major coronal Cobb angle and T1-S1 spinal height were not significantly different between the 2 groups. Compared with the GRI group, the VEPTR group had less correction in thoracic kyphosis $(23 \% \pm 12 \%$ vs $44 \% \pm 16 \%, p<0.001)$ after the index surgery and experienced a greater correction loss in thoracic kyphosis $(46 \% \pm$ $18 \%$ vs $11 \% \pm 8 \%, p<0.001)$ at the latest follow-up. Although the increase in the proximal junctional angle was not significantly different (VEPTR: $7^{\circ} \pm 4^{\circ}$ vs GRI: $8^{\circ} \pm 5^{\circ}, p=0.569$ ), the incidence of proximal junctional kyphosis was relatively lower in the VEPTR group (VEPTR: $18.2 \%$ vs GRI: $22.7 \%$ ). No significant changes in the spinopelvic parameters were observed, while the sagittal vertical axis showed a tendency toward a neutral position in both groups. The overall complication rate was higher in the VEPTR group than in the GRI group (72.7\% vs $54.5 \%$ ).

CONCLUSIONS The VEPTR had coronal correction and spinal growth results similar to those with GRI. In the sagittal plane, however, the VEPTR was not comparable to the GRI in controlling thoracic kyphosis. Thus, for hyperkyphotic EOS patients, GRI is recommended over VEPTR.

https://thejns.org/doi/abs/10.3171/2017.7.PEDS17233

KEY WORDS vertical expandable prosthetic titanium rib; growing rod; sagittal spinal profile; early-onset scoliosis; spine

$\mathrm{I}$ $\mathrm{N}$ recent years, various types of spine growth-friendly instrumentation have been used with the goal of minimizing spinal deformities while maximizing spine and thoracic growth in children with early-onset scoliosis (EOS). Based on repeated distractive forces they exert on the spine, vertical expandable prosthetic titanium ribs (VEPTRs) and growing rod instrumentation (GRI) have been classified as distraction-based instrumentation by Skaggs et al. ${ }^{20}$

As originally described by Campbell and Hell-Vocke, ${ }^{5}$

ABBREVIATIONS EOS = early-onset scoliosis; GRI = growing rod instrumentation; $\mathrm{LL}=$ lumbar lordosis; $\mathrm{PI}=$ pelvic incidence; $\mathrm{PJA}=$ proximal junctional angle; $\mathrm{PJK}=$ proximal junctional kyphosis; PT = pelvic tilt; SS = sacral slope; SVA = sagittal vertical axis; TK = thoracic kyphosis; UIV = upper instrumentation vertebra; VEPTR = vertical expandable prosthetic titanium rib.

SUBMITTED May 2, 2017. ACCEPTED July 17, 2017.

INCLUDE WHEN CITING Published online October 6, 2017; DOI: 10.3171/2017.7.PEDS17233.

* Drs. Z. Chen and Li contributed equally to this work. 
VEPTR was applied to young children with thoracic insufficiency syndromes related to congenital spine and rib anomalies. The favorable control of complex spinal deformities stimulated surgeons to expand the VEPTR's indications to EOS of idiopathic, neuromuscular, and syndromic etiologies. . $^{210,11,15,22}$

However, it is known that the major difference between VEPTR and GRI is that VEPTR selects ribs as proximal anchor sites, while GRI has anchors only at the spine either proximally or distally. Thus, although VEPTR and GRI encourage spinal growth via regular lengthening, they can create different results because of different fixation characteristics and mechanisms in correcting scoliosis.

To date, previous studies comparing the VEPTR and GRI have focused on coronal plane deformity, spinal height, and the space available for the lungs.,14,17,23 Apart from a higher prevalence of complications reported with the use of VEPTR, there are solid data supporting satisfactory correction with the VEPTR and GRI in the coronal plane. To the best of our knowledge, however, there is a paucity of comparisons between the VEPTR and GRI as regards the evolution of the sagittal spinal profile in EOS. Thus, in this study, we aimed to compare the effects of VEPTR and GRI constructs on the sagittal profile of the EOS population and to demonstrate the complications related to changes in sagittal alignment during the lengthening period.

\section{Methods}

After obtaining approval from our institutional review board, we performed a retrospective review of a single database of patients with EOS. The patients in the VEPTR group were included in the study if they met the following criteria: 1) age of 10 years or younger at the time of the index VEPTR surgery, 2) main thoracic curve scoliosis; 3) at least 2 lengthening procedures, and 4) a follow-up duration of more than 2 years. Exclusion criteria were 1) a prior history of spine surgery, and 2) a distal anchor at the sacrum or pelvis. The GRI patients selected from our database were well matched to the VEPTR group in terms of sex, etiology, age at the index surgery ( \pm 10 months), preoperative thoracic kyphosis $\left(\mathrm{TK} ; \pm 20^{\circ}\right)$, duration of follow-up, lengthening procedure numbers and interval, number of rib-to-spine or spine-to-spine rods (single vs dual), and location of proximal and distal spinal foundations.

At the index surgery, VEPTR and GRI implants were placed with small separate incisions, and only cephalad and caudal anchors sites were exposed subperiosteally. The vertebral segments between anchors were not dissected in order to prevent autofusion. The rods were tunneled in a submuscular manner to reduce soft tissue complications and wound infections.

The major coronal Cobb angle, T1-S1 spinal height, T2-T12 TK, L1-S1 lumbar lordosis (LL), proximal junctional angle (PJA), pelvic incidence (PI), pelvic tilt (PT), sacral slope (SS), and sagittal vertical axis (SVA) were measured on standing full-spine radiographs before and after the index surgery and at the latest follow-up. The PJA was defined as the angle between the caudal endplate of the upper instrumentation vertebra (UIV) or the vertebra parallel to the upper instrumented rib and the cephalad endplate of the second suprajacent vertebra above the UIV or the vertebra parallel to the upper instrumented rib. Proximal junctional kyphosis (PJK) was diagnosed using 2 criteria: $\left.{ }^{9} 1\right) \mathrm{PJA} \geq 10^{\circ}$ and 2) PJA at least $10^{\circ}$ greater than the preoperative measurement. The presence of both criteria was necessary to be considered PJK. For patients with definitive fusion, the latest follow-up referred to the time point prior to the definitive fusion.

Inpatient and outpatient records and operative notes were reviewed retrospectively for complications in each group. Implant-related complications included rib cradle migration with or without rib fracture, rod fracture, and dislodgment of pedicle screw, hook, or rod. Alignmentrelated complications consisted of PJK and sagittal imbalance. Visceral, neurological, or vascular injury and superficial or deep infection were classified as general complications.

Statistical analyses were performed using SPSS version 20.0 software (IBM Corp.). Comparisons between variables of interest were made using the independent samples t-test. Chi-square tests were performed to compare the distribution of etiology, proximal spinal foundation, or distal spinal foundation between the VEPTR and GRI groups. Significance was defined as $\mathrm{p}<0.05$.

\section{Results Demographic Data}

A total of 12 VEPTR patients met the inclusion criteria, 11 of whom had complete data available for analysis. There were 8 boys and 3 girls in the VEPTR group, while there were 16 boys and 6 girls in the GRI group. The etiologies, age at index surgery, duration of followup, number of lengthening procedures, and intervals were similar between these 2 groups (Table 1). In the VEPTR group, 7 patients had dual rib-to-spine rods, while 4 had a single rib-to-spine rod, accompanied by unilateral rib-torib constructs in 2 of the 4 . In the GRI group, there were 7 patients with a single rod and 15 patients with dual rods. Proximal foundation levels for the VEPTR patients ranged from the second rib to the fifth rib and from T-2 to T-5 for GRI patients. Distal foundation levels ranged from L-2 to L-4 for both groups. Four VEPTR and 2 GRI patients who reached skeletal maturity had undergone removals of the growth-friendly instrumentations and definitive fusion.

\section{Major Coronal Cobb Angle and T1-S1 Spinal Height}

The magnitudes of the major coronal Cobb angle were similar between the 2 groups before and after the index surgery and at the latest follow-up (Table 2). Annual T1$\mathrm{S} 1$ growth was $0.85 \pm 0.17 \mathrm{~cm} /$ year for the VEPTR group and $0.97 \pm 0.19 \mathrm{~cm} /$ year for the GRI group $(\mathrm{p}=0.087)$ during the lengthening period.

\section{Evolution of the Sagittal Profile}

There was no statistical difference in preoperative TK between the VEPTR and GRI groups $\left(52^{\circ} \pm 11^{\circ}\right.$ vs $56^{\circ}$ $\pm 13^{\circ}, \mathrm{p}=0.389$; Table 2 ). In the VEPTR group, TK notably decreased after the index surgery but significantly increased over time with subsequent distractions (Fig. 1). 
TABLE 1. Summary of demographic data in 22 patients with EOS

\begin{tabular}{|c|c|c|c|}
\hline Parameter & $\begin{array}{l}\text { VEPTR } \\
\text { Group }\end{array}$ & $\begin{array}{l}\text { GRI } \\
\text { Group }\end{array}$ & $\begin{array}{c}p \\
\text { Value }\end{array}$ \\
\hline Etiology & & & 0.812 \\
\hline Congenital & 6 & 11 & \\
\hline Idiopathic & 2 & 4 & \\
\hline Neuromuscular & 2 & 5 & \\
\hline Syndromic & 1 & 2 & \\
\hline $\begin{array}{l}\text { Age at the index sur- } \\
\text { gery in yrs (range) }\end{array}$ & $6.8 \pm 2.5(3.1-9.8)$ & $6.4 \pm 1.8(4.2-9.4)$ & 0.601 \\
\hline $\begin{array}{l}\text { Duration of FU in yrs } \\
\text { (range) }\end{array}$ & $5.9 \pm 1.4(4.4-7.8)$ & $5.8 \pm 1.9(4.1-7.2)$ & 0.878 \\
\hline $\begin{array}{l}\text { No. of lengthening } \\
\text { procedures (range) }\end{array}$ & $6.8 \pm 1.6(5-8)$ & $6.6 \pm 2.0(4-8)$ & 0.775 \\
\hline $\begin{array}{l}\text { Lengthening intervals } \\
\text { in mos (range) }\end{array}$ & $9.9 \pm 2.3(9-12)$ & $10.2 \pm 1.9(8-11)$ & 0.693 \\
\hline $\begin{array}{l}\text { Location of proximal } \\
\text { foundation }\end{array}$ & & & 0.888 \\
\hline 2nd rib/T-2 & 2 & 4 & \\
\hline 3rd rib/T-3 & 4 & 9 & \\
\hline 4th $\mathrm{rib} / \mathrm{T}-4$ & 4 & 7 & \\
\hline 5th $\mathrm{rib} / \mathrm{T}-5$ & 1 & 2 & \\
\hline $\begin{array}{l}\text { Location of distal } \\
\text { foundation }\end{array}$ & & & 0.549 \\
\hline L-2 & 1 & 2 & \\
\hline$L-3$ & 7 & 11 & \\
\hline$L-4$ & 3 & 9 & \\
\hline
\end{tabular}

FU = follow-up.

Means are presented \pm SD.

The overall increase in TK from pre-index surgery to the latest follow-up was $24^{\circ} \pm 10^{\circ}$. Compared with the GRI group, the VEPTR group had a lower correction rate of TK $(23 \% \pm 12 \%$ vs $44 \% \pm 16 \%, \mathrm{p}<0.001)$ after the index surgery and experienced a greater loss of TK correction $(46 \% \pm 18 \%$ vs $11 \% \pm 8 \%, \mathrm{p}<0.001)$ during the lengthening period.

Lumbar lordosis was similar between the 2 groups preoperatively, postoperatively, and at the latest follow-up. In both groups, LL significantly decreased after the index surgery and then returned to the pre-index surgery level at the latest follow-up. Compared with preoperative values, PJA in both groups significantly increased during the lengthening procedures (Figs. 1 and 2); however, the increasing amount of PJA was not significantly different between the 2 groups (VEPTR: $7^{\circ} \pm 4^{\circ}$ vs GRI: $8^{\circ} \pm 5^{\circ}, \mathrm{p}=0.569$ ).

In both groups, the mean change in PI was not statistically significant $(\mathrm{p}>0.05)$. Similarly, the mean SS and PT did not show any significant change during the lengthening period $(\mathrm{p}>0.05)$. As shown in Table 2 , significant improvement was observed in the SVA, which indicated a tendency toward a neutral position in both groups.

\section{Complications}

Table 3 shows a higher complication rate for the VEPTR group than for the GRI group (72.7\% vs $54.5 \%)$. In the
TABLE 2. Radiographic measurements for both groups through treatment

\begin{tabular}{|c|c|c|c|}
\hline Parameter & $\begin{array}{l}\text { VEPTR } \\
\text { Group }\end{array}$ & $\begin{array}{l}\text { GRI } \\
\text { Group }\end{array}$ & $\begin{array}{c}p \\
\text { Value }\end{array}$ \\
\hline \multicolumn{4}{|l|}{ Major coronal Cobb angle $\left(^{\circ}\right)$} \\
\hline Pre-index surgery & $74 \pm 17$ & $72 \pm 16$ & 0.742 \\
\hline Post-index surgery & $50 \pm 13$ & $46 \pm 15$ & 0.457 \\
\hline Latest FU & $47 \pm 15$ & $44 \pm 12$ & 0.595 \\
\hline \multicolumn{4}{|l|}{ T1-S1 spinal height (cm) } \\
\hline Pre-index surgery & $24.5 \pm 6.4$ & $24.7 \pm 7.3$ & 0.939 \\
\hline Post-index surgery & $27.4 \pm 9.2$ & $27.8 \pm 8.7$ & 0.904 \\
\hline Latest FU & $32.4 \pm 6.5$ & $33.4 \pm 8.1$ & 0.725 \\
\hline \multicolumn{4}{|l|}{ T2-12 TK $\left(^{\circ}\right)$} \\
\hline Pre-index surgery & $52 \pm 11$ & $56 \pm 13$ & 0.389 \\
\hline Post-index surgery & $40 \pm 14$ & $32 \pm 12$ & 0.098 \\
\hline Latest FU & $64 \pm 17$ & $38 \pm 16$ & $<0.001$ \\
\hline Post-index surgery to latest FU & $24 \pm 10$ & $6 \pm 12$ & $<0.001$ \\
\hline \multicolumn{4}{|l|}{ L1-S1 LL $\left(^{\circ}\right)$} \\
\hline Pre-index surgery & $-54 \pm 12$ & $-52 \pm 13$ & 0.672 \\
\hline Post-index surgery & $-43 \pm 17$ & $-45 \pm 12$ & 0.698 \\
\hline Latest FU & $-57 \pm 14$ & $-50 \pm 13$ & 0.165 \\
\hline Pre-index surgery to latest FU & $-3 \pm 7$ & $2 \pm 8$ & 0.088 \\
\hline \multicolumn{4}{|l|}{$\operatorname{PJA}\left({ }^{\circ}\right)$} \\
\hline Pre-index surgery & $6 \pm 3$ & $8 \pm 3$ & 0.081 \\
\hline Post-index surgery & $11 \pm 4$ & $15 \pm 3$ & 0.003 \\
\hline Latest FU & $13 \pm 3$ & $16 \pm 4$ & 0.036 \\
\hline Pre-index surgery to latest FU & $7 \pm 4$ & $8 \pm 5$ & 0.569 \\
\hline \multicolumn{4}{|l|}{$\mathrm{PI}\left({ }^{\circ}\right)$} \\
\hline Pre-index surgery & $33 \pm 13$ & $34 \pm 16$ & 0.859 \\
\hline Post-index surgery & $34 \pm 14$ & $35 \pm 14$ & 0.848 \\
\hline Latest FU & $37 \pm 11$ & $37 \pm 13$ & 1.000 \\
\hline Pre-index surgery to latest FU & $4 \pm 6$ & $3 \pm 5$ & 0.616 \\
\hline \multicolumn{4}{|l|}{$\operatorname{SS}\left({ }^{\circ}\right)$} \\
\hline Pre-index surgery & $34 \pm 16$ & $37 \pm 17$ & 0.630 \\
\hline Post-index surgery & $38 \pm 18$ & $37 \pm 16$ & 0.872 \\
\hline Latest FU & $40 \pm 15$ & $39 \pm 16$ & 0.864 \\
\hline \multicolumn{4}{|l|}{$\mathrm{PT}\left({ }^{\circ}\right)$} \\
\hline Pre-index surgery & $-1 \pm 12$ & $-3 \pm 13$ & 0.672 \\
\hline Post-index surgery & $-4 \pm 10$ & $-2 \pm 11$ & 0.616 \\
\hline Latest FU & $-5 \pm 8$ & $-4 \pm 7$ & 0.715 \\
\hline \multicolumn{4}{|l|}{ SVA (mm) } \\
\hline Pre-index surgery & $-21 \pm 17$ & $-18 \pm 16$ & 0.622 \\
\hline Post-index surgery & $10 \pm 18$ & $-2 \pm 17$ & 0.070 \\
\hline Latest FU & $-3 \pm 10$ & $2 \pm 11$ & 0.215 \\
\hline
\end{tabular}

Means are presented \pm SD.

VEPTR group, 6 unplanned revision surgeries were required for 6 implant-related complications, including 4 rib cradle migrations and 2 pedicle screw pullouts. In the GRI group, 9 unplanned revision surgeries were performed for 9 implant-related complications consisting of 4 rod fractures, 3 pedicle screw pullouts, and 2 rod dislodgements. 

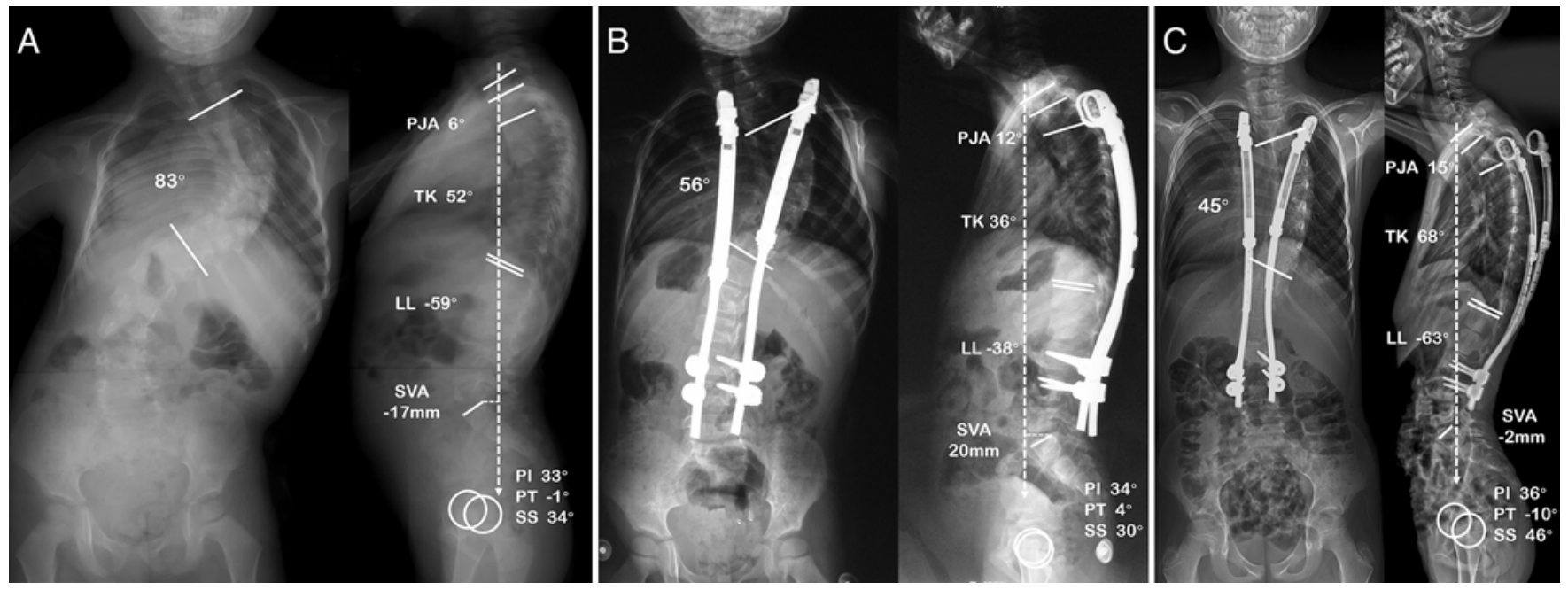

FIG. 1. A 3.4-year-old boy diagnosed with idiopathic infantile scoliosis was treated with a VEPTR device. During 8 years' follow-up, he had 8 lengthening procedures. A and B: After the index surgery, T2-12 TK was changed from $52^{\circ}$ to $36^{\circ}$, and PJA increased from $6^{\circ}$ to $12^{\circ}$. C: At the latest follow-up, T2-12 TK was $68^{\circ}$ and PJA was $15^{\circ}$. He experienced right-sided rib cradle migration.

Proximal junctional kyphosis, as a major alignment-related complication, was more frequent in the GRI group than in the VEPTR group (22.7\% vs $18.2 \%$ ).

Two pleura ruptures occurred intraoperatively in the VEPTR group and were managed at the end of the procedure. Two superficial infections were observed in each of the VEPTR and GRI groups, and all were controlled with antibiotics and regular dressing. One VEPTR patient underwent implant removal as a result of deep infection 9 months after the fourth lengthening procedure. One GRI patient with deep infection had 2 debridement procedures, and then the wound healed. No death, neurological deficit, pneumonia, or other complications occurred.

\section{Discussion}

The current study revealed similar correction in the coronal plane but different evolutions in the sagittal plane between the VEPTR and GRI groups. In the VEPTR group, TK demonstrated a significant decrease after the index surgery but a significant correction loss at the latest follow-up. On the contrary, TK in the GRI group demonstrated a significant decrease after the index surgery and remained steady until the latest follow-up. Boseker et al. ${ }^{4}$ defined the normal value of T2-12 TK as a range of $20^{\circ}-50^{\circ}$ in healthy children. In our study, the T2-12 TK at the latest follow-up in the VEPTR and GR groups was $64^{\circ} \pm 17^{\circ}$ and $38^{\circ} \pm 16^{\circ}$, respectively. Therefore, based on the reference value, the value of T2-12 TK in the VEPTR group is revealed as hyperkyphosis. Reinker et al. ${ }^{16}$ reviewed 14 patients who had undergone VEPTR treatment for early-onset kyphoscoliosis. Eleven patients (78\%) had progression of T2-12 TK, with an average increase of $23^{\circ}$. These results demonstrate that repeated distraction forces associated with rib anchors in the VEPTR construct may be more kyphogenic, which could pose a risk of kyphosis gain with the VEPTR during the lengthening period. In previous studies, ${ }^{3,6,18,19}$ it was revealed that GRI can effectively correct hyperkyphotic EOS, with the sagittal pro- file successfully restored to a normal range. The change in sagittal plane alignment reveals that GRI has a strong tendency to decrease TK in patients with a preoperative hyperkyphotic sagittal modifier. Thus, for hyperkyphotic EOS patients, GRI is preferable to VEPTR.

In the VEPTR group, LL demonstrated a decrease after the index surgery and returned to the preoperative level at the latest follow-up. In the GRI group, LL had a consistent slight decrease post-index surgery and during the followup. However, the angle difference in the VEPTR group between pre-index surgery and the latest follow-up was similar to that in the GRI group $\left(-3^{\circ} \pm 7^{\circ}\right.$ vs $2^{\circ} \pm 8^{\circ}$, p $=0.088$ ). A simultaneous reciprocal change of LL in the VEPTR group responded to the increase of TK during the lengthening period.

The change in PJA between the pre-index surgery and the latest follow-up was $7^{\circ} \pm 4^{\circ}$ in the VEPTR group and $8^{\circ} \pm 5^{\circ}$ in the GRI group $(\mathrm{p}=0.569)$. Although it was not statistically significant, the incidence of PJK was slightly lower in the VEPTR group than in the GRI group (18.2\% vs $22.7 \%$, respectively). In the study by El-Hawary et al., ${ }^{8}$ the incidence of PJK in VEPTR patients was also relatively lower than that in GRI patients (17\% vs $25 \%$ at immediate follow-up, and $25 \%$ vs $31 \%$ at final follow-up). The above results demonstrate a tendency to a higher incidence of PJK in the GRI group. Although the influence of proximal spinal anchors in the GRI construct on the development of junctional kyphosis remains to be studied, stronger spinal purchase via pedicle screws or hooks may provide more stress concentration on the proximal junction of the spine. Conversely, the VEPTR cradles provide less sagittal control but offer a smooth transition to uninstrumented levels.

Sagittal spinopelvic balance has been documented in healthy children and adolescents. Mac-Thiong et al..$^{13}$ reported that a small increase in PI is observed as age progresses and that this increase is correlated with the increase in PT and that SS is relatively stable. Konieczny et al. ${ }^{12}$ compared a cohort of VEPTR patients with healthy controls and demonstrated no changes in PI, PT, and SS 

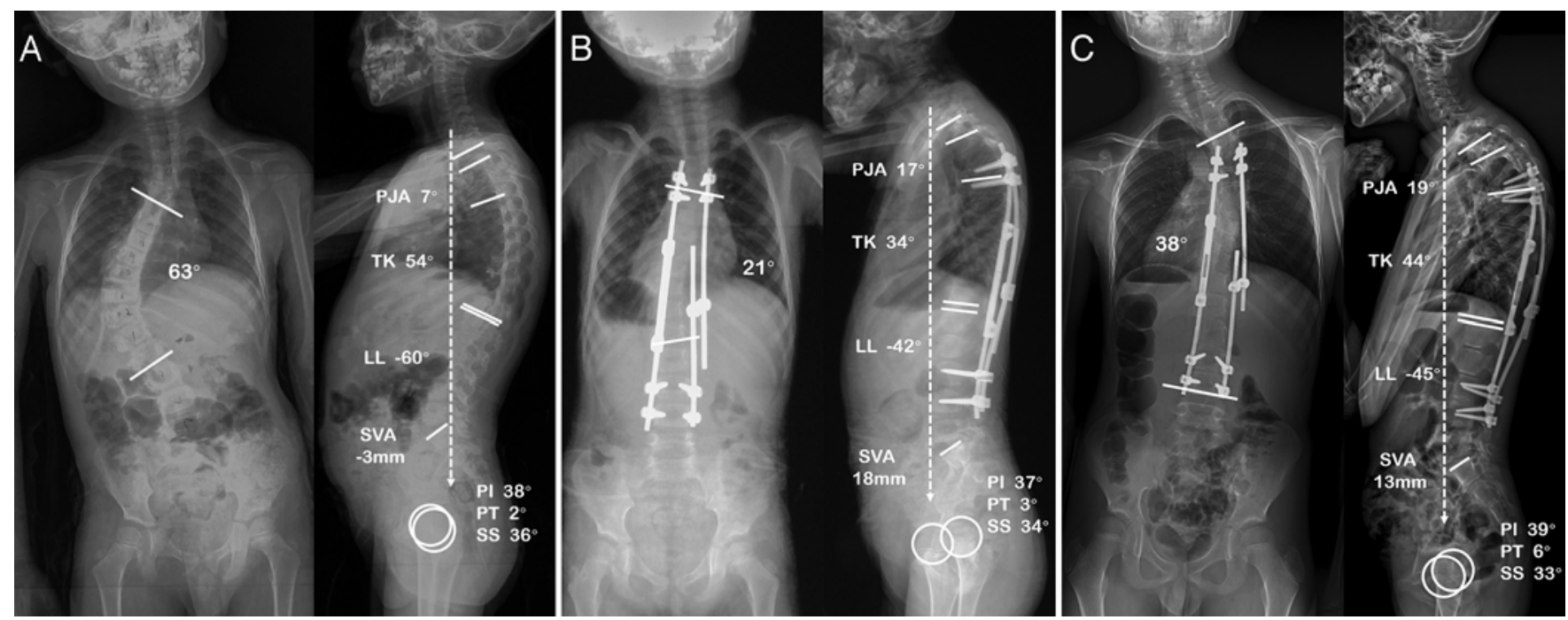

FIG. 2. A 5.2-year-old boy with idiopathic infantile scoliosis was treated with growing rods. During a follow-up of 5 years 7 months, he had 6 lengthening procedures. A and B: After the index surgery, T2-12 TK was corrected from $54^{\circ}$ to $34^{\circ}$, and PJA increased from $7^{\circ}$ to $17^{\circ}$. C: After the sixth lengthening procedure, T2-12 TK was $44^{\circ}$ and PJA was $19^{\circ}$. Proximal junctional kyphosis was noted.

between the 2 groups during growth. In the current study, absolute increases in PI from preoperatively to the latest follow-up were $4^{\circ} \pm 6^{\circ}$ and $3^{\circ} \pm 5^{\circ}$ over a period of several lengthening procedures in the VEPTR and GRI groups, respectively, but these increases were not statistically significant. In addition, we also observed that the values for SS and PT were relatively stable during the treatment with the VEPTR or the GRI technique.

Several authors have described the effect of the GRI technique on sagittal balance. Sponseller et al. ${ }^{21}$ noted that sagittal balance was improved from 5.2 to $3.5 \mathrm{~cm}$ in 36 GRI patients. Akbarnia et al. ${ }^{1}$ studied a series of 23 patients treated with the dual-GRI technique and found that SVA was corrected from 3.72 to $2.33 \mathrm{~cm}$ after initial lengthening and to $3.92 \mathrm{~cm}$ at the latest follow-up. In our study, there were similar results between the VEPTR and GRI groups in the restoration of sagittal balance, with a tendency toward a neutral position.

In terms of complications, we found a higher complication rate in the VEPTR group than in the GRI group (72.7\% vs $54.5 \%)$. Most of the complications for both groups were implant related and needed revision surgeries. Anchor dislodgement and rod breakage were the most common implant-related complications in the GRI group. Instead, rib cradle migration with or without rib fracture occurred most frequently in the VEPTR group. Deep infection was noted in both groups. The patient in the VEPTR group with a deep infection underwent removal of the implants as a result of a stubborn infection at the rib cradle site. We rationalized that if the soft tissue coverage at the rib cradle site was not good enough, the wound would not easily heal when the rib cradle repeatedly rubbed against the soft tissue.

Our study has several limitations. Its main limitation is its relatively smaller sample size. Another limitation is the inherent drawback of EOS with its complex and heterogeneous pathologies. Moreover, this study lacked a healthy control group with which to compare the VEPTR and GRI patients as regards the changes in sagittal profiles. Ideally, such a longitudinal study would allow adequate selection of healthy subjects for accurate assessment. Unfortunately, such methodology would require serial radiographs in healthy children and thus is almost impossible because of ethical concerns. Despite these limitations, the study has several notable strengths. The average follow-up was over 5 years, and 4 VEPTR and 2 GRI patients underwent definitive fusion. Additionally, all patients in this single-center study were treated by surgeons working ac-

TABLE 3. Summary of complications among 33 EOS patients treated with VEPTR or GRI

\begin{tabular}{ccc}
\hline \multirow{2}{*}{ Complication } & \multicolumn{2}{c}{$\mathrm{N}(\mathrm{n}, \%)$} \\
\cline { 2 - 3 } & VEPTR Group & GRI Group \\
\hline Implant related & \\
\hline $\begin{array}{c}\text { Rib cradle migration w/ } \\
\text { or w/o rib fracture }\end{array}$ & $4(3,27.3 \%)$ & \\
\hline Rod fracture & 0 & $4(3,13.6 \%)$ \\
\hline $\begin{array}{c}\text { Pedicle screw, hook, or } \\
\text { rod dislodgment }\end{array}$ & $2(2,18.2 \%)$ & $5(4,18.2 \%)$ \\
\hline Alignment related & & \\
\hline PJK & $2(2,18.2 \%)$ & $5(5,22.7 \%)$ \\
\hline Sagittal imbalance & $1(1,9 \%)$ & $1(1,4.5 \%)$ \\
\hline General & & \\
\hline Pleura rupture & $2(2,18.2 \%)$ & 0 \\
\hline Superficial infection & $2(2,18.2 \%)$ & $2(2,9.0 \%)$ \\
\hline Deep infection & $1(1,9 \%)$ & $1(1,4.5 \%)$ \\
\hline Total adverse events & $14(8,72.7 \%)$ & $18(12,54.5 \%)$ \\
\hline
\end{tabular}

$\mathrm{N}=$ number of complication events; $\mathrm{n}=$ number of cases with at least 1 complication; $\%=$ percentage of cases with at least 1 complication. 
cording to the same surgical decision making, which minimized variations in operative strategies and techniques for patients and thus maximally guaranteed consistency of surgical results.

\section{Conclusions}

Similar results in coronal correction and spinal growth were demonstrated in patients treated with VEPTR and GRI. In the sagittal plane, however, the VEPTR was not comparable to the GRI in controlling TK. Thus, for hyperkyphotic EOS patients, GRI is recommended over VEPTR. Moreover, the VEPTR is best indicated for congenital scoliosis associated with chest wall deformity, rather than idiopathic EOS.

\section{Acknowledgments}

This work was supported by the National Natural Science Foundation of China (Grant No. 81401848), the Nanjing Science and Technology Development Project (YKK14053), and Jiangsu Provincial Key Medical Center (2016).

\section{References}

1. Akbarnia BA, Marks DS, Boachie-Adjei O, Thompson AG, Asher MA: Dual growing rod technique for the treatment of progressive early-onset scoliosis: a multicenter study. Spine (Phila Pa 1976) 30 (17 Suppl):S46-S57, 2005

2. Astur N, Flynn JM, Flynn JM, Ramirez N, Glotzbecker M, van Bosse HJ, et al: The efficacy of rib-based distraction with VEPTR in the treatment of early-onset scoliosis in patients with arthrogryposis. J Pediatr Orthop 34:8-13, 2014

3. Atici Y, Akman YE, Erdogan S, Sari S, Yavuz U, Carkci E, et al: The effect of growing rod lengthening technique on the sagittal spinal and the spinopelvic parameters. Eur Spine J 24:1148-1157, 2015

4. Boseker EH, Moe JH, Winter RB, Koop SE: Determination of "normal" thoracic kyphosis: a roentgenographic study of 121 "normal" children. J Pediatr Orthop 20:796-798, 2000

5. Campbell RM Jr, Hell-Vocke AK: Growth of the thoracic spine in congenital scoliosis after expansion thoracoplasty. $\mathbf{J}$ Bone Joint Surg Am 85-A:409-420, 2003

6. Chen Z, Qiu Y, Zhu Z, Li S, Chen X, Sun X: How does hyperkyphotic early-onset scoliosis respond to growing rod treatment? J Pediatr Orthop [epub ahead of print], 2016

7. Dede O, Motoyama EK, Yang CI, Mutich RL, Walczak SA, Bowles AJ, et al: Pulmonary and radiographic outcomes of VEPTR (vertical expandable prosthetic titanium rib) treatment in early-onset scoliosis. J Bone Joint Surg Am 96:1295-1302, 2014

8. El-Hawary R, Sturm P, Cahill P, Samdani A, Vitale M, Gabos $\mathrm{P}$, et al: What is the risk of developing proximal junctional kyphosis during growth friendly treatments for early-onset scoliosis? J Pediatr Orthop 37:86-91, 2017

9. Glattes RC, Bridwell KH, Lenke LG, Kim YJ, Rinella A, Edwards C II: Proximal junctional kyphosis in adult spinal deformity following long instrumented posterior spinal fusion: incidence, outcomes, and risk factor analysis. Spine (Phila Pa 1976) 30:1643-1649, 2005

10. Hasler CC, Mehrkens A, Hefti F: Efficacy and safety of VEPTR instrumentation for progressive spine deformities in young children without rib fusions. Eur Spine J 19:400408, 2010

11. Heflin JA, Cleveland A, Ford SD, Morgan JV, Smith JT: Use of rib-based distraction in the treatment of early-onset sco- liosis associated with neurofibromatosis type 1 in the young child. Spine Deform 3:239-245, 2015

12. Konieczny MR, Ehrlich AK, Krauspe R: Vertical expandable prosthetic titanium ribs (VEPTR) in early-onset scoliosis: impact on thoracic compliance and sagittal balance. J Child Orthop 11:42-48, 2017

13. Mac-Thiong JM, Berthonnaud E, Dimar JR II, Betz RR, Labelle H: Sagittal alignment of the spine and pelvis during growth. Spine (Phila Pa 1976) 29:1642-1647, 2004

14. Mayer $\mathrm{OH}$, Redding G: Early changes in pulmonary function after vertical expandable prosthetic titanium rib insertion in children with thoracic insufficiency syndrome. J Pediatr Orthop 29:35-38, 2009

15. O'Brien A, Roth MK, Athreya H, Reinker K, Koeck W, Patil $\mathrm{V}$, et al: Management of thoracic insufficiency syndrome in patients with Jeune syndrome using the $70 \mathrm{~mm}$ radius vertical expandable prosthetic titanium rib. J Pediatr Orthop 35:783-797, 2015

16. Reinker K, Simmons JW, Patil V, Stinson Z: Can VEPTR ${ }^{\circledR}$ control progression of early-onset kyphoscoliosis? A cohort study of VEPTR ${ }^{\circledR}$ patients with severe kyphoscoliosis. Clin Orthop Relat Res 469:1342-1348, 2011

17. Sankar WN, Acevedo DC, Skaggs DL: Comparison of complications among growing spinal implants. Spine (Phila Pa 1976) 35:2091-2096, 2010

18. Schroerlucke SR, Akbarnia BA, Pawelek JB, Salari P, Mundis GM Jr, Yazici M, et al: How does thoracic kyphosis affect patient outcomes in growing rod surgery? Spine (Phila Pa 1976) 37:1303-1309, 2012

19. Shah SA, Karatas AF, Dhawale AA, Dede O, Mundis GM Jr, Holmes L Jr, et al: The effect of serial growing rod lengthening on the sagittal profile and pelvic parameters in earlyonset scoliosis. Spine (Phila Pa 1976) 39:E1311-E1317, 2014

20. Skaggs DL, Akbarnia BA, Flynn JM, Myung KS, Sponseller PD, Vitale MG: A classification of growth friendly spine implants. J Pediatr Orthop 34:260-274, 2014

21. Sponseller PD, Yang JS, Thompson GH, McCarthy RE, Emans JB, Skaggs DL, et al: Pelvic fixation of growing rods: comparison of constructs. Spine (Phila Pa 1976) 34:17061710,2009

22. White KK, Song KM, Frost N, Daines BK: VEPTR ${ }^{\mathrm{TM}}$ growing rods for early-onset neuromuscular scoliosis: feasible and effective. Clin Orthop Relat Res 469:1335-1341, 2011

23. Yazici M, Emans J: Fusionless instrumentation systems for congenital scoliosis: expandable spinal rods and vertical expandable prosthetic titanium rib in the management of congenital spine deformities in the growing child. Spine (Phila Pa 1976) 34:1800-1807, 2009

\section{Disclosures}

The authors report no conflict of interest concerning the materials or methods used in this study or the findings specified in this paper.

\section{Author Contributions}

Conception and design: Sun, X Chen. Acquisition of data: Xu. Analysis and interpretation of data: $\mathrm{Z}$ Chen, Li. Drafting the article: Z Chen. Critically revising the article: Qiu, Zhu. Approved the final version of the manuscript on behalf of all authors: Sun. Statistical analysis: Li. Study supervision: Sun.

\section{Correspondence}

Xu Sun, Spine Surgery, Drum Tower Hospital, Nanjing University Medical School, 321 Zhongshan Rd., Nanjing 210008, China. email: drsunxu@163.com. 